\title{
Chemodectoma of lung
}

\author{
F. J. FAWCETT AND E. M. HUSBAND
}

SYNOPSIS The histological and histochemical features of a primary chemodectoma of lung are described and compared with previously reported pulmonary chemodectomata. The tumour is of interest because, although there is physiological evidence that chemoreceptors are present in the lung, they have not yet been located anatomically.

Although normal chemoreceptor tissue has not been demonstrated in the lung there is physiological evidence that pulmonary chemoreceptors exist in animals (Aviado, Pontius, and Schmidt, 1949; Dawes and Comroe, 1954).

In 1958 Heppleston described a peripherally situated lung tumour measuring $4 \mathrm{~cm} . \times 3 \mathrm{~cm}$. $\times$ $3 \mathrm{~cm}$. which histologically resembled a carotid-body tumour. Korn, Bensch, Liebow, and Castleman in 1960 described multiple minute pulmonary tumours which they had found in 12 out of 3,635 necropsies. They believed that the tumours were derived from chemoreceptor tissue because of the typical appearance, their multiplicity, and their close relationship to pulmonary venules. Since then, other authors have described similar minute tumours which had been found on histological examination of random blocks of lung taken at necropsy (Spencer, 1962; Zak and Chabes, 1963). The finding of such tumours lends support to the physiological evidence that chemoreceptors are present in the lung. The purpose of this paper is to describe a lung tumour, similar in many respects to that described by Heppleston, which we believe to be a chemodectoma.

\section{CLINICAL HISTORY}

The patient was a 66-year-old married woman who was found to have a rounded opacity in the upper zone of the right upper lobe on routine chest radiography. She had no symptoms and the only abnormality on physical examination was a blood pressure of $240 / 125 \mathrm{~mm}$. $\mathrm{Hg}$. Right upper lobectomy was carried out as the lesion appeared to be neoplastic. Twenty-four hours after operation she had a cardiac arrest; resuscitation was successful but she remained semi-comatose until she died three days later from a second cardiac arrest.

\section{PATHOLOGY}

The lobectomy specimen was received in buffered formol saline. The tumour was $1.5 \mathrm{~cm}$. in diameter, and was situated immediately beneath the visceral pleura at the apex of the right upper lobe. The cut surface of the tumour was greyish with dark red flecks and it was difficult to differentiate from the surrounding lung tissue. Histologically the central part of the tumour consisted of polyhedral cells with scanty, eosinophilic cytoplasm some of which appeared to line vascular channels but the majority were arranged in clusters (Fig. 1). The cells at the periphery had more abundant eosinophilic, vacuolated cytoplasm and they were also arranged in clusters (Fig. 2). The cell nests, both at the periphery and in the centre, were surrounded by fine reticulin networks and numerous thin-walled vascular channels (Fig. 3). A muscular pulmonary artery and a bronchiole passed through the tumour and a pulmonary vein was present at one edge.

The chromaffin reaction was not obtained by Gomori's method. The tumour cells did not exhibit autofluorescence and argentaffin granules were not demonstrated by the diazonium method. The periodic acid-Schiff, Bests' carmine, and mucicarmine reactions were negative and the cells did not contain fat. Nerve fibres were not demonstrated by Holmes' method.

\section{NECROPSY FINDINGS}

Two small recent infarcts were present in the upper part of the right middle lobe. No tumours were found in the remainder of the right lung or in the left lung. The left lung was inflated and fixed by formalin vapour and was therefore available for particularly thorough examination. There was moderate left ventricular hypertrophy, the thickness of the wall being $1.6 \mathrm{~cm}$. and the overall heart weight $470 \mathrm{~g}$. The sites where chemodectomata, or paragangliomata, have been described were examined, and no other tumours were identified.

\section{DISCUSSION}

The present tumour has the histological features of 




FIG. 1

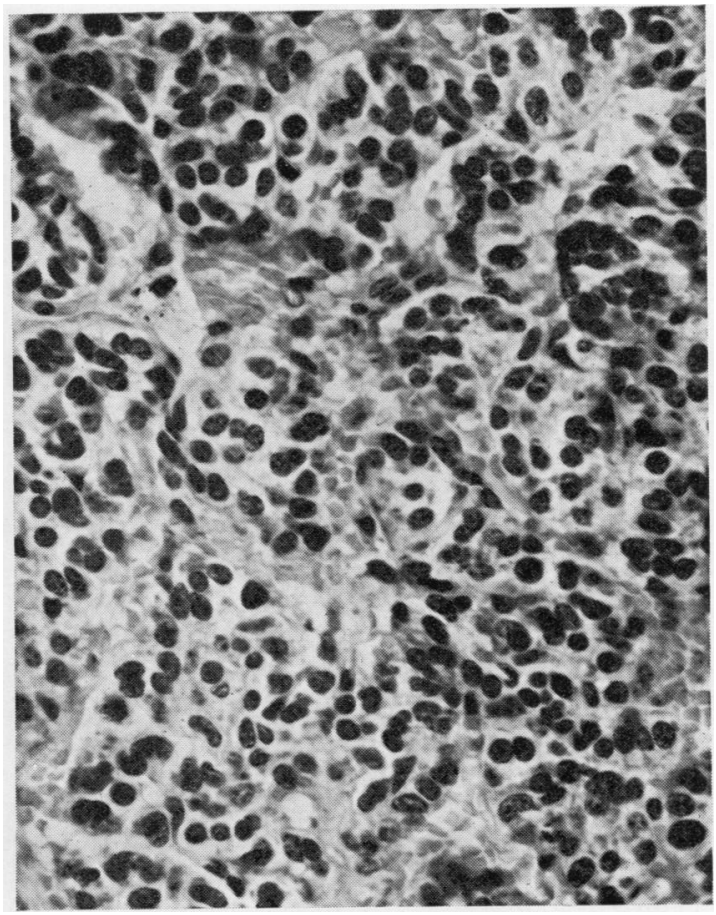

FIG. 2

FIG. 1. Central part of the tumour showing nests of polyhedral cells separated by distended thin-walled vascular channels. Haematoxylin and eosin $\times 300$.

FIG. 2. Peripheral part of tumour showing more compact arrangement of cell nests. Haematoxylin and eosin $\times 400$.

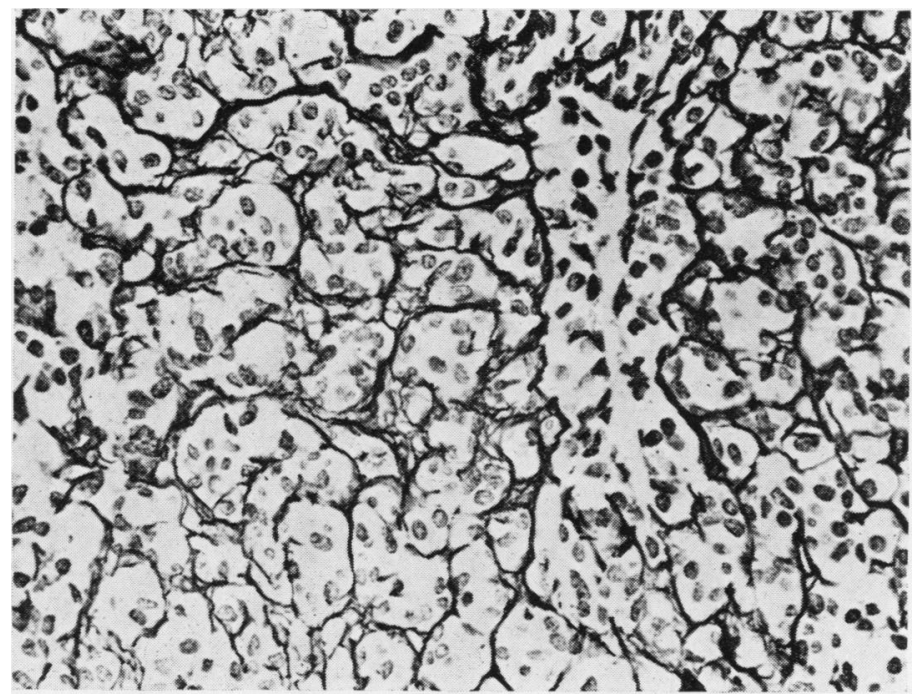

FIG. 3. Reticulin impregnation showing network of reticulin around the cell nests and the thin-walled blood vessels. Gomori's method $\times 300$. 
both the 'usual', and 'angiomatous' types of carotid body tumour described by Le Compte (1948). Paragangliomata have been described at many different sites (Heppleston, 1958). As no tumour was found on examination of these sites at necropsy this appears to be a primary tumour of lung. Minute tumours similar to those described by Korn et al. (1960) as chemodectomas were not found on histological examination of many blocks of lung taken both at necropsy and from the right upper lobectomy specimen.

The tumour we describe closely resembles the carotid-body like tumour described by Heppleston (1958) in its subpleural situation, the histological appearance, and the histochemical findings. Because of its peripheral, subpleural situation we feel that this is unlikely to be an unusual type of adenoma. Willis (1953) was of the opinion that the bronchial adenoma did not occur at the periphery of the lung. It also closely resembles the minute tumours described by Korn et al. in 1960 which also had the appearance of the angiomatous type of carotid-body tumour. The vacuolated cells at the periphery of the tumour appear to be similar to the vacuolated cells described by Korn and his associates, in which neither fat nor P.A.S.-positive material could be demonstrated. Although the nature of the tumours described by Korn et al. is doubtful, it seems more likely that they are hyperplastic or hamartomatous lesions of chemoreceptor tissue rather than true neoplasms (Spencer, 1962). The present tumour appears to be a benign neoplasm, but because of the histological similarity between the two both appear to be derived from the same tissue.

The tumour described as a non-chromaffin paraganglioma of lung by Mostecký, Lichtenberg, and Kalus (1966) differed from those other tumours in that the cells contained argentaffin granules, P.A.S.positive material, and fat. The authors do not comment on the reticulin framework which is of great importance in tumours of chemoreceptor origin.

Pryse-Davis, Dawson, and Westbury (1964) investigated the chromaffin reaction and catechole amine content of four carotid body tumours and found chromaffin granules in one tumour which also had a high noradrenaline content. The chromaffin reaction was negative in the other three tumours though the catechole amine content was somewhat elevated. The chromaffin reaction of this tumour was negative but the tissue had been fixed for five days in formol saline before it was transferred to the chromate solution. According to Culling (1963) the chromaffin reaction is only rarely positive after formalin fixation. Noradrenaline in formalin-fixed tissues exhibits a greenish autofluorescence but the cells in this tumour were negative. It is of some interest that the fixative was coloured a very dark brown which is suggestive of release of catechol amine from the tissue. Unfortunately the action of formalin made chemical estimation of the catechol amine content impossible. The patient had been hypertensive, with a blood pressure of 240/125 $\mathrm{mm} . \mathrm{Hg}$, and at necropsy there was left ventricular hypertrophy and no obvious cause for the hypertension. However the post-operative fall in blood pressure was not unduly great.

\section{REFERENCES}

Aviado, D. M., Jr., Pontius, R. G., and Schmidt, C. F. (1949). J. Pharmacol. exp. Ther., 97, 420.

Culling, C. F. A. (1963). Handbook of Histopathological Techniques, 2nd ed., p. 380. Butterworth, London.

Dawes, G. S., and Comroe, J. H., Jr. (1954). Physiol. Rev., 34, 167. Heppleston, A. G. (1958). J. Path. Bact., 75, 461.

Korn, D., Bensch, K., Liebow, A.A., and Castleman, B. (1960). Amer. J. Path., 37, 641.

LeCompte, P. M. (1948). Ibid. 24, 305.

Mostecky, H., Lichtenberg, J., Kalus, M. (1966). Thorax, 21, 205.

Pryse-Davies, J., Dawson, I. M. P., and Westbury, G. (1964). Cancer (Philad.), 17, 185.

Spencer, H. (1962). Pathology of the Lung, p. 691. Pergamon Press, Oxford.

Willis, R. A. (1953). Pathology of Tumours, 2nd ed., p. 380. Butterworth, London.

Zak, F. G., and Chabes, A. (1963). J. Amer. med. Ass., 183, 887.

\section{ADDENDUM}

Since this paper was accepted for publication, we have had the opportunity of examining a second tumour with identical histological and histochemical features.

The patient, a 55-year-old woman, was found to have a rounded opacity in the right middle lobe on mass miniature radiography. Her only symptom was slight exertional dyspnoea. Her pre-operative blood pressure ranged from $130 / 60 \mathrm{~mm}$. $\mathrm{Hg}$ to $190 / 110 \mathrm{~mm}$. $\mathrm{Hg}$, and during the operation for excision of the tumour she had a period of profound hypotension and a cardiac arrest. Her postoperative recovery was uneventful.

We should like to thank Dr. C. D. Cruickshank for letting us examine this second tumour. 